\title{
The human c-fos serum response factor and the yeast factors GRM/PRTF have related DNA-binding specificities
}

\author{
Timothy E. Hayes, Piali Sengupta, and Brent H. Cochran \\ Center for Cancer Research and Department of Biology, Massachusetts Institute of Technology, Cambridge, Massachusetts \\ 02139 USA
}

\begin{abstract}
One of the elements that mediates growth factor and serum inducibility of the human c-fos gene is a region of dyad symmetry that lies between nucleotides -320 and -299 of the human gene. A mammalian protein specifically binds to this sequence element and has been termed the serum response factor (SRF). Gel-shift analysis and competition experiments demonstrate that there is a factor in the yeast Saccharomyces cerevisiae that binds specifically to the human c-fos SRE. The methylation interference pattern of the yeast factor is identical to that of the mammalian SRF. Regulatory elements of cell-type-specific genes in yeast have homologies to the c-fos SRE and compete for binding of both the mammalian and yeast factors to the SRE. Antisera to the gene product of the MCM1 locus react with the yeast SRE-binding factor. These data suggest that this yeast protein is closely related or identical to the factors [general regulator of mating type (GRM) and pheromone/receptor transcription factor (PRTF)] that are required for the regulation of cell-type-specific genes in yeast.
\end{abstract}

[Key Words: c-fos; serum response factor; GRM/PRTF; S. cerevisiae; MCM1]

Received August 25, 1988; revised version accepted October 31, 1988.

The growth of mammalian cells in culture is strictly regulated by a variety of polypeptide mitogens. Some of these polypeptide growth factors, such as the plateletderived growth factor, activate signal transduction processes that lead to the activation of new gene expression. The expression of these genes, and especially of the c-fos and c-myc proto-oncogenes, appears to play a key role in the mitogenic response to growth factors (for review, see Cochran 1985).

The c-fos gene is promptly and transiently induced by a variety of extracellular stimuli (Cochran et al. 1984; Greenberg and Ziff 1984; Muller et al. 1984). In fibroblasts, c-fos transcription is activated within a few minutes of serum addition to quiescent cells. This transcriptional activation peaks by $30 \mathrm{~min}$ and returns to basal levels within 1-2 hr. A dyad symmetry element located between -299 and -320 of the human c-fos gene has been shown to be sufficient for mediating the serum responsiveness of this gene (Treisman 1985, 1986; Gilman et al. 1986; Prywes and Roeder 1986; Greenberg et al. 1987). This element is capable of being activated by platelet-derived growth factor, by the tumor promoter phorbol myristate acetate (PMA), and by epidermal growth factor (EGF) and nerve growth factor (NGF) in the appropriate cell type (Fisch et al. 1987; Gilman 1988; Sheng et al. 1988). A similar element is located upstream of the cytoskeletal actin genes in Xenopus and will confer serum responsiveness as well (Mohun et al. 1987).
Nuclear extracts of several cell types have been found to contain a protein factor that interacts specifically with this serum response element (SRE) (Gilman et al. 1986; Prywes and Roeder 1986, 1987; Treisman 1986; Greenberg et al. 1987). This $67-\mathrm{kD}$ protein is believed to play a central role in the regulation of c-fos gene induction. However, this factor is present in both induced and uninduced cells, and no changes or modifications of this factor have yet been correlated with c-fos gene transcription (Gilman et al. 1986; Prywes and Roeder 1986; Treisman 1986; Hayes et al. 1987b; Sheng et al. 1988).

Recently, it has become increasingly evident that there are substantial similarities between transcriptional regulation in yeast and that in mammalian cells. A yeast TATA-box-binding factor functions in a mammalian transcription system (Buratowski et al. 1988; Cavallini et al. 1988). A yeast upstream activation site has been shown to function in HeLa cells, and the SV40 early promoter has been shown to function in fission yeast (Jones et al. 1988; Kakidani and Ptashne 1988; Webster et al. 1988). In addition, several mammalian transcription factors have close relatives in corresponding yeast factors. Such factors include the heat shock transcription factor, CCAAT-box-binding factors, and AP1 (Harshman et al. 1988; Struhl 1987; Widerrecht et al. 1987; Chodosh et al. 1988).

Here, we report the identification of a factor in the yeast Saccharomyces cerevisiae whose binding speci- 
ficity closely resembles that of the mammalian serum response factor (SRF). In addition, we provide evidence that this yeast factor is closely related to factor(s) involved in the maintenance of cell-type-specific gene expression in yeast.

\section{Results}

A S. cerevisiae factor has the same binding specificity as the mammalian $S R F$

Whole-cell extracts were prepared from yeast and assayed for the ability to form specific complexes with an end-labeled oligonucleotide made to the sequence of the human c-fos SRE. Binding complexes were analyzed by DNA gel electrophoresis as shown in Figure 1 /Garner and Revzin 1981; Singh et al. 1986), where it can be seen that a single major complex and one minor complex are formed with the yeast extracts. The complexes formed with the yeast extracts run with a slightly greater mobility than those formed from the mammalian cell extract. Addition of unlabeled homologous competitor DNA to the binding reaction effectively competes for

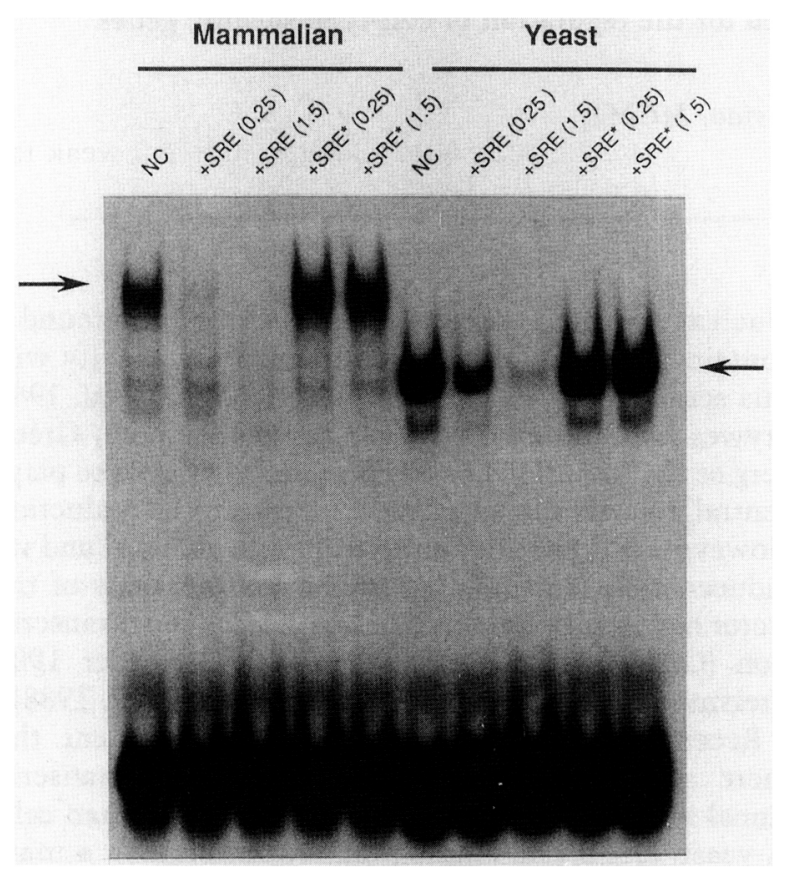

Figure 1. A factor from yeast specifically binds to the human c-fos SRE. An oligonucleotide containing human SRE was end labeled and used a probe in band-shift assays, as described in Materials and methods. This probe was allowed to incubate with either nuclear extracts of mammalian cells or with extracts from the yeast $S$. cerevisiae (L3248), as described in Materials and methods. Some of the binding reactions were done in the presence of excess unlabeled competitor oligonucleotides; (SRE) unlabeled probe; (SRE*) a mutant SRE oligonucleotide that has $G$ to $C$ transversions at the known SRF contact points (for sequences, see Materials and methods). Arrows indicate the positions of specific complexes. (NC) No competitor. Numbers indicate picomoles of unlabeled competitor double-stranded oligonucleotides added to the reaction. the formation of these complexes. Addition of a mutant SRE oligonucleotide, which has been shown previously not to bind mammalian SRF, failed to compete for binding of the yeast factor to the SRE. Thus, these complexes are formed as a result of sequence-specific interactions.

The regions of protein-DNA contact between the yeast factor and the human sequence element were analyzed further by methylation interference assay. A fragment of the human c-fos gene was labeled at one end with ${ }^{32} \mathrm{P}$ and reacted with dimethylsulfate to methylate principally guanine residues. Yeast extracts were incubated with this DNA, and protein-DNA complexes were subsequently fractionated on band-shift gels. The sequence-specific complexes and the free probe were eluted from the gel and chemically cleaved at methylated guanines. The resulting DNAs were analyzed on sequencing gels and processed for autoradiography.

As shown in Figure 2, methylation of two Gs on each of the top and the bottom strands of the SRE interfered with the binding of the factor. These four symmetric residues are precisely the locations of the interference sites for the mammalian factor (Gilman et al. 1986; Treisman 1986). No other guanine nucleotides from this probe interfered with binding when methylated. Thus, the mammalian and yeast factors recognize the human c-fos SRE in a similar, if not identical, manner.

\section{The human c-fos SRE functions as a weak regulatory element in yeast}

To determine whether the human c-fos SRE functions as a regulatory element in yeast, we inserted this element in varying copy numbers and positions upstream of a yeast CYC1-lacZ fusion gene. These chimeric constructs were then transfected into yeast cells on multicopy plasmids and analyzed for $\beta$-galactosidase activity. When the SRE site is positioned upstream of a CYC1 promoter that has been deleted for both UAS1 and UAS2 but retains the TATA boxes, a very small (less than twofold) enhancement of $\beta$-galactosidase activity is measured. When three copies of the SRE are placed upstream of the CYCl promoter, a greater activation (approximately fivefold is seen. However, this activation is minimal, as compared to UAS2, an authentic yeast upstream activation sequence (see Fig. 3).

In addition, the effect of the c-fos SRE on UAS2-mediated activation of the CYC1 promoter was examined. When the CYC1 UAS2 is present upstream of the promoter, its expression is regulated by carbon source and is subject to glucose repression (Guarante et al. 1983). We have used a mutant UAS2 sequence (UP1) that exhibits an increased basal level of expression in the presence of glucose relative to the wild-type UAS2 but is still inducible when grown on a nonfermentable carbon source such as lactate (Guarente et al. 1984). When the human c-fos SRE is positioned between UAS2 and the TATA boxes, a reduction of $\beta$-galactosidase expression down to $20 \%$ of control levels is observed (Fig. 3). The degree of repression observed increases with increasing copies of 


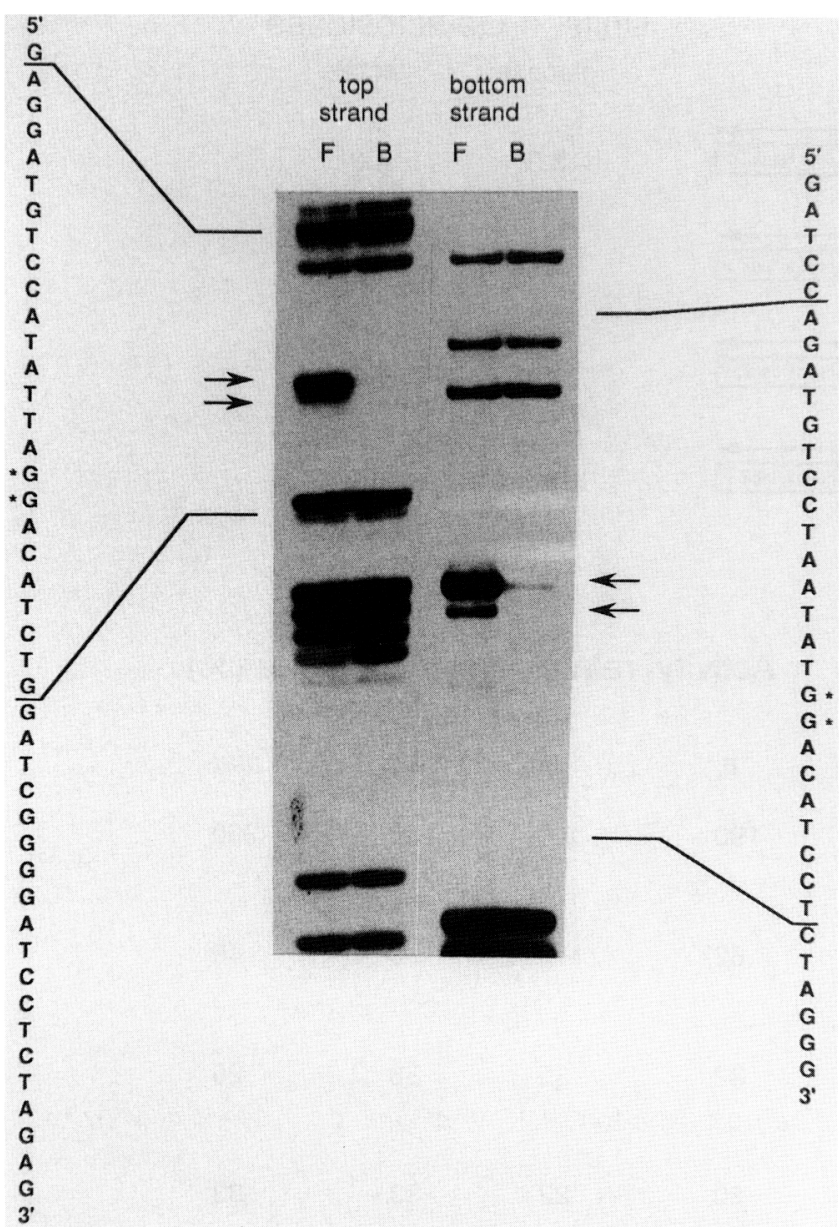

Figure 2. Methylation interference pattern of the S. cerevisiae SRE-binding factor. Yeast whole-cell extracts were incubated in a binding reaction with an end-labeled, dimethylsulfate-treated c-fos upstream fragment containing the SRE, as described in Materials and methods. Specific complexes and free probe were separated on preparative band-shift gels. The DNAs were eluted from the gel, chemically cleaved at methylated guanine nucleotides, and fractionated on sequencing gels. Guanine residues that interfere with binding when methylated are indicated by arrows. The sequence of the region is given at either side of the gels, with the locations of the Gs that showed interference indicated by asterisks. Bracketed sequences are from the c-fos SRE. The sequences outside the brackets are derived from the vector. The location of the indicated guanines in the c-fos sequence was determined by comparison to a sequencing ladder (not shown). (F) DNA from free probe; (B) DNA from specific complexes.

the SRE cloned between UAS2 and the TATA boxes. This diminution of $\beta$-galactosidase activity was not due to a reduction in plasmid copy number, as detected by Southern blot analysis (data not shown). Neither was reduction in activity due to the small increase of spacing between UAS2 and the TATA boxes ( $90 \mathrm{bp}$ ) because insertion of mutant SRE oligonucleotides that fail to bind the yeast factor in vitro (Fig. 1) does not give rise to decreased levels of $\beta$-galactosidase activity /data not shown).
When the SRE was positioned upstream of UAS2, repression of $\beta$-galactosidase was not observed. In fact, the level of $\beta$-galactosidase activity increased two- to threefold with the SRE upstream. Increasing the number of copies of the SRE upstream of the UAS2 did not enhance expression further.

$S$. cerevisiae has three distinct cell types-a, $\alpha$, and $\mathbf{a} / \boldsymbol{\alpha}$ diploids - that are determined by the expression of the products of the mating-type locus. All of the UAS2SRE-CYC1-lacZ plasmids were tested for $\beta$-galactosidase expression in a cells, $\alpha$ cells, a $/ \alpha$ diploids, or mat ${ }^{-}$ cells. (mat ${ }^{-}$cells are mutants that express none of the gene products of the mating-type locus in yeast.) As shown in Figure 3, the modulatory effects of the SRE on UAS2 were not strongly cell type dependent. As a control, an authentic yeast cell-type-specific regulatory element, the MATa2-regulated operator of the STE6 gene, was positioned between UAS2 and the TATA boxes of CYC1-lacZ. This operator represses expression of a-specific genes in $\alpha$ cells and $\mathbf{a} / \alpha$ diploids. As expected, expression from this plasmid was repressed in $\alpha$ and $\mathbf{a} / \alpha$ diploids.

Thus, by itself, the SRE has a slight activating effect on CYC1 promoter activity. In addition, it can modulate the activity of UAS2 either upward or downward, depending on its relative position. This modulation persists even when the cells are grown on lactate, which fully induces UAS2 (data not shown). The modulations are independent of cell type and are relatively weak for the most part. However, the magnitude of the effects can be at least fivefold for trimers of the SRE.

Regulatory elements of cell-type-specific genes in yeast are related to the human $S R E$

Sequence comparisons of the c-fos SRE to known yeast regulatory elements suggest similarities between the SRE and the regulatory elements of cell-type-specific yeast genes. A comparison between the c-fos SRE, the Xenopus cytoskeletal actin SRE, and the cell-type-specific yeast elements is shown in Figure 4.

The repression of a-specific gene expression in $\alpha$ cells is one of the best studied examples of repression in yeast (Brent 1985). The mating-type locus gene product $\alpha 2$ is required for the repression of a-specific genes, such as $\alpha$-factor receptor and a-mating factor in $\alpha$ cells (Johnson and Herskowitz 1985). A common sequence element located upstream of several a-specific genes has been found to be necessary for this repression. The $\alpha 2$ repressor has been shown to bind to this element (Sauer et al. 1988). The central region of the $\alpha 2$ operator bears a striking resemblance to the central region of the human c-fos SRE. It has been noted previously that this $\alpha 2$ operator core region is related to a palindromic element termed the $\mathrm{P}$ box, which is part of the upstream activation sequences of several $\alpha$-specific genes (Bender and Sprague 1987) (for comparison, see Fig. 4). All of these yeast elements and the SRE have a core motif approximating $5^{\prime}-\mathrm{CC}(\mathrm{T} / \mathrm{A})_{6} \mathrm{GG}-3^{\prime}$. We have performed competition experiments with oligonucleotides containing these 
Hayes et al.

Units B-Galactosidase
glucose lactate

TATA $\underset{\text { cyci:iacz }}{\longrightarrow}$

3.3

4.3

4.0

5.0

18

n.d.

160

750

Activity relative to UAS2 alone (\%)

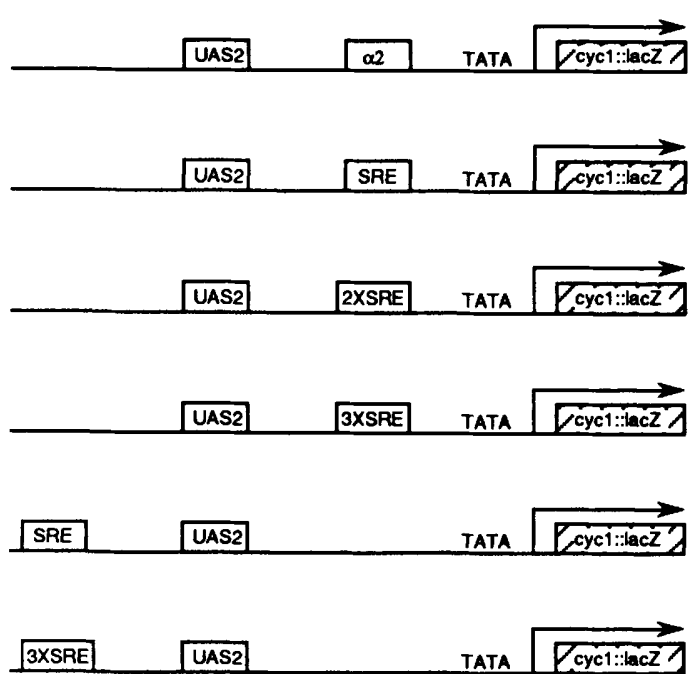

a

190

62

32

20

210

350 $\alpha$

2.0

110

35

22

130 $a / \alpha$

13

73

36

33

110

220 mat-

260

45

26

33

250

280

Figure 3. Assay for SRE function in yeast. Oligonucleotides of the c-fos SRE or $\alpha 2$ operator of the STE6 gene were cloned upstream of the indicated CYC1-lacZ constructs and transfected into $\mathbf{a}, \alpha, \mathbf{a} / \alpha$ or mat ${ }^{-}$strains of yeasts. The $\mathbf{a}, \alpha$, and $\mathbf{a} / \alpha$ strains are isogenic. The resulting strains were grown on SD with glucose or lactate and assayed for $\beta$-galactosidase activity, as described in Materials and methods. The percentages of expression given are the numbers relative to the expression given by the UAS2-CYC1-lacZ parent plasmid. All numbers given are averages of at least triplicate experiments. Note that the UAS2 used here is the UP1 mutant that is not fully repressed in glucose. (n.d.) Value not determined.

elements to determine whether they compete with the human c-fos SRE for binding to the yeast factor.

Figure 5 shows the results of a band-shift gel where the yeast factor-SRE complex has been competed with the $\alpha 2$ repressor-operator, an $\alpha 2$ repressor-operator mutant, and the P box from the UAS of the $\alpha$-specific STE3 gene. The SRE, $\alpha 2$ operator, and the P(STE3) oligonucleotides all competed for binding to the SRE probe. The $\alpha 2$ operator shows the strongest and most complete competition for the yeast factor, even stronger than self(SRE) competition. P(STE3) shows weaker competition, indicating a slightly lower affinity for the factor. Quantitative competition experiments (not shown) indicate that the affinity of the SRE for the yeast factor is approximately twofold lower than that of the $\alpha 2$ operator. The affinity of the P box of STE3 is $\sim 10$ - to 20 -fold lower than that of the $\alpha 2$ operator. A quadruple point mutant of the $\alpha 2$ repressor operator that contains $\mathrm{G}$ to $\mathrm{C}$ transversions at all the positions predicted to interfere with binding based on the SRE homology fails to compete for specific complex formation (for the exact sequence, see Materials and methods).

The weaker binding of the $\mathrm{P}$ box of STE3 relative to that of the SRE and the $\alpha 2$ operator is consistent with the fact that this sequence is only homologous at three of the four Gs in the core region of the sequence. An 


\begin{tabular}{|c|c|c|}
\hline \multicolumn{2}{|c|}{ C-EOS } & GGATGTCCATATTAGGACATCT \\
\hline \multirow{7}{*}{$\begin{array}{l}\text { a-specific } \\
\text { genes }\end{array}$} & ACTIN & AGATGCCCATATTTGGCGATCT \\
\hline & . . & .... \\
\hline & STE 6 & CATGTAATTACCTAATAGGGAAATT TACACGCT \\
\hline & BAR 1 & CATGTAATTACCGAAAAAGGAAATTACATGGCG \\
\hline & STE2 & CATGTACTTACCCAATTAGGAAATTTACATGGT \\
\hline & MFa1 & TGTGTAATTACCCAAAAAGGAAATT TACATGTT \\
\hline & MFa2 & CATGTATTTACCTATTCGGGAAATTTACATGAC \\
\hline \multirow{4}{*}{$\begin{array}{l}\alpha \text {-specific } \\
\text { genes }\end{array}$} & $\operatorname{STE} 3$ & $\cdots \underset{\text { TTTCCTAATTAGTGTC }}{\cdots}$ \\
\hline & $\mathrm{MF} \alpha 1 \mathrm{~A}$ & СТTССTAATTAGGCCA \\
\hline & $\mathrm{MF} \alpha 1 \mathrm{~B}$ & TTTCCTAATTAGTCCT \\
\hline & $\mathrm{MF} \boldsymbol{\alpha} 2$ & TTTCTTCATTGGTACA \\
\hline
\end{tabular}

Figure 4. Sequence homologies between the c-fos SRE and cell-type-specific regulatory elements of $S$. cerevisiae. The c-fos sequence is that of the human c-fos SRE (Treisman 1987). The actin sequence is the dyad symmetry element from the Xenopus cytoskeletal actin gene (Mohun et al. 1987). The sequences from the operators of a-specific genes are taken from Johnson and Herskowitz (1985). The sequences of the $P$ boxes of the indicated $\alpha$-specific genes are from Bender and Sprague (1987). The regions of homology are indicated by boldface type.

oligonucleotide that has a perfectly palindromic $\mathrm{P}$ box and a $4 / 4$ match for the relevant guanines competes at least twice as effectively as the natural $\mathrm{P}$ box element (data not shown). The actual affinity of the perfectly palindromic $\mathrm{P}$ box is probably even higher but is difficult to determine precisely due to the propensity of this oligonucleotide to form hairpin loops rather than full duplexes under low ionic strength conditions. A mutant SRE that has three out of four of the core cytosines and guanines mutated does not compete for binding. As expected from the competition experiments, using the $\alpha 2$ operator and $\mathrm{P}\{S T E 3\}$ oligonucleotides directly as probes in band-shift experiments yields complexes that have the same mobility and pattern as those formed with the SRE. The SRE competed for the formation of these complexes (Fig. 7 and data not shown).

Figure 5 also shows a parallel experiment to determine the ability of the same DNAs to compete for the binding of the mammalian SRF to the human c-fos SRE. All except the mutant SRE and the mutant $\alpha 2$ repressor-operator competed for the mammalian SRF binding to some degree. The relative effectiveness of the competition of each of these oligonucleotides was the same for the mammalian factor as it was for the yeast factor, with one exception. The human SRE competed slightly more effectively (less than twofold) for the SRF than the yeast $\alpha 2$ operator did. This result again indicates that the DNA recognition sites of the mammalian and yeast factors are quite similar.

Keleher et al. (1988) have shown that there are two yeast factors that bind to the $\alpha 2$ operator in a cooperative manner to give repression. One factor is the MAT 22 gene product. This factor is only expressed in $\alpha$ and $\mathbf{a} / \alpha$ diploid cells and contacts the flanks of the operator. A second factor, which they have termed GRM /for general regulator of mating type), contacts the center of the operator and is expressed in all cell types. Because the center region of the operator is where the SRE homologies lie, it is likely that the yeast SRE-binding factor is identical or closely related to GRM. In an analogous manner, two factors appear to be required for expression of $\alpha$-specific genes in $\alpha$ cells. One of these factors is the mating-type locus gene product $\alpha 1$, and the other is a non-cell-type-specific factor that binds to the $\mathrm{P}$ box of $\alpha$-specific UASs. Bender and Sprague (1987) have termed this factor PRTF (pheromone/receptor transcription factor). Because the P boxes of $\alpha$-specific genes are similar in sequence to the center of the $\alpha 2$ repressor-operators (see Fig. 4), it has been proposed that PRTF and GRM are the same factor. To further examine the possibility that the yeast SRE-binding factor is related to GRM/PRTF, extracts from all the yeast cell types were examined for SRE-binding activity.

From the band-shift experiment shown in Figure 6, it can be seen that a specific competable complex of the same mobility was formed from factors present in extracts of all yeast cell types. The $\mathbf{a}, \alpha$, and $\mathbf{a} / \alpha$ diploids are isogenic, except for the MAT locus. The mat ${ }^{-}$cells express none of the mating-type locus gene products. Thus, expression of the SRE-binding factor is independent of cell type and products of the MAT locus. This result is consistent with the idea that the yeast SREbinding factor is GRM/PRTF. In addition, it rules out the alternative hypothesis that the $\alpha 1$ or $\alpha 2$ repressor is the binding factor because these genes are not expressed in a or mat ${ }^{-}$cells.

Keleher et al. (1988) and Passmore et al. (1988) have suggested that GRM/PRTF may be the product of the MCM1 locus of yeast. Mutations in this locus were identified originally on the basis of their failure to maintain certain minichromosomes (Maine et al. 1984). Null

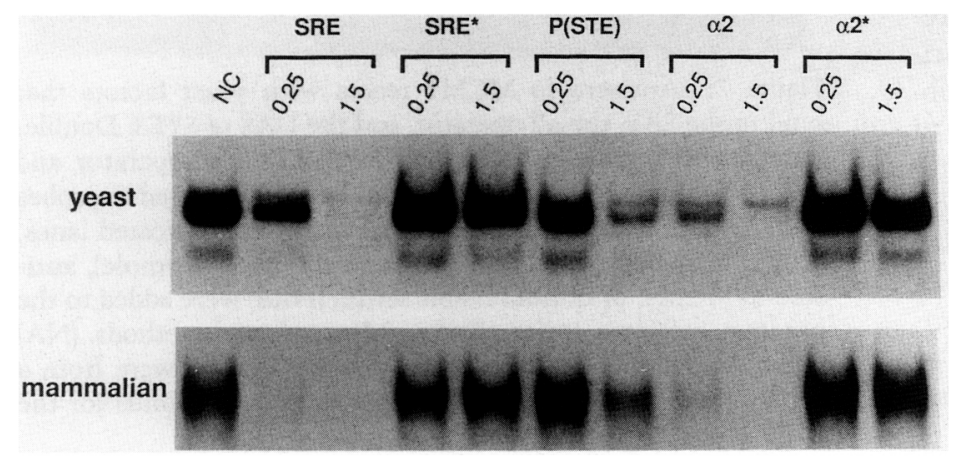

Figure 5. Mammalian and yeast SRE-binding factors are competed by cell-type-specific regulatory elements from yeast. An oligonucleotide of the human SRE (L3248) was end-labeled and used as a probe for band-shift assays with yeast and mammalian extracts, as described in Materials and methods. Sequences of double-stranded oligonucleotides used as competitor DNAs are described in Materials and methods. (NC) No competitor; (SRE) c-fos SRE; (SRE*) nonbinding mutant of SRE, $[\mathrm{P}(S T E)] \mathrm{P}$ box of the $\alpha$-specific UAS of STE3; $(\alpha 2)$ operator of the a-specific gene STE6; $\left(\alpha 2^{*}\right)$ mutant of $\alpha 2$ operator in region of c-fos homology. Numbers given are picomoles of competitor DNAs added to the binding reactions. 


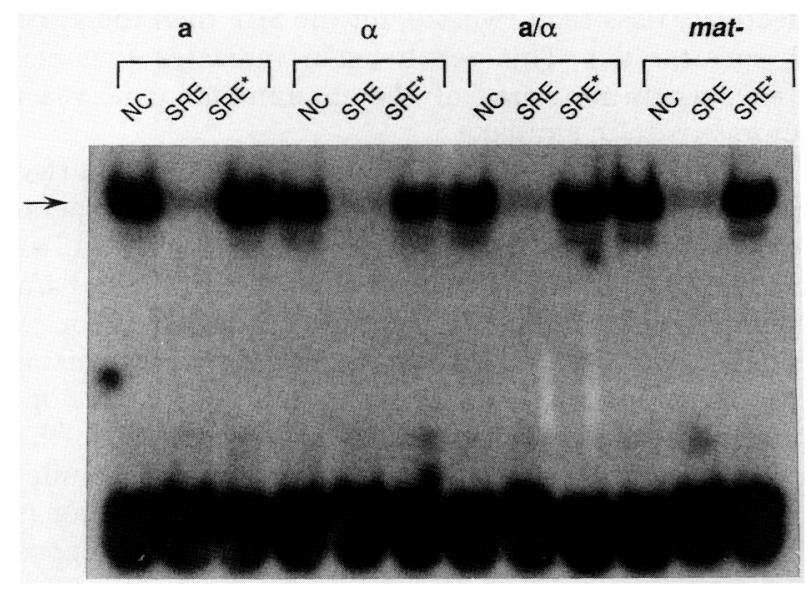

Figure 6. Binding of the yeast factor to the human c-fos SRE is not dependent on yeast cell type or product of the mating-type locus. An oligonucleotide of the human SRE was end-labeled and used as a probe in a band-shift assay, as described in Materials and methods. This probe was used in binding assays from yeast extracts prepared from isogenic a, $\alpha$, or $a / \alpha$ diploid cells. mat $^{-}$extracts from a yeast strain expressing no mating-type locus gene products; (NC) no competitor; (SRE) competition with unlabeled SRE oligonucleotide; (SRE*) competition with unlabeled SRE mutant oligonucleotide. Arrows indicate the location of specific complexes.

mutations in this locus are lethal, but the $m c m 1-1$ allele is a point mutant that also has an $\alpha$-specific sterile phenotype and shows reduced expression of $\alpha$-specific genes. The sequence of this gene suggests that it bears similarities to other transcription factors (Dubois et al. 1987; Passmore et al. 1988). In addition, Keleher et al. (1988) have reported that extracts of $m \mathrm{~cm} 1-1$ cells have reduced levels of GRM-binding activity, as compared to wild type. Thus, MCM1 could potentially encode GRM or PRTF, or both.

We have determined whether anti-MCM1 antibody will react with the yeast factors that bind to the SRE, the $\alpha 2$ repressor-operator, and the $\alpha$-specific UAS of STE3. Polyclonal rabbit anti-MCM1 sera were incubated with yeast extracts, and oligonucleotides made to each of these regulatory regions prior to being fractionated on band-shift gels (Fig. 7). With each probe, the specific band migrated with a slower mobility when the extracts were incubated with the antisera. Normal rabbit serum failed to shift the specific complex. Inclusion of unlabeled homologous competitor DNAs in the binding reactions effectively competed for formation of the antiMCM1-specific complex (data not shown). The shift observed with the anti-MCM1 sera occurred irrespective of whether the antisera were incubated with the extract before or after addition of the probe. This result indicates that the factors that complex with the c-fos SRE, the $\alpha 2$ operator, and the UAS of STE3 have a common component that is either the $M C M 1$ gene product or antigenically related to it. The anti-MCM1 sera failed to shift the specific complex formed between the SRE and mammalian cell extracts (data not shown).

\section{Discussion}

In this paper, we have described a factor from $S$. cerevisiae that interacts with the mammalian c-fos SRE. The mammalian and yeast factors that bind the SRE show identical methylation interference patterns across the element. Oligonucleotides made to regulatory elements from yeast, which have sequences similar to the mammalian c-fos SRE, show affinities for the yeast factor that are similar to those each shows for the mammalian factor. Interestingly, all of these elements have common core motifs closely resembling $5^{\prime}-\mathrm{CC}(\mathrm{A} / \mathrm{T})_{6} \mathrm{GG}-3^{\prime}$. Comparison of the known SRF-binding sites from vertebrate regulatory elements indicates that this motif is conserved among them and that the exact sequence of the As and Ts in the core may not be a strong determinant of binding (Mohun et al. 1987).

In mammalian cells, the SRE functions as a regulatable enhancer element. Treatment of mammalian cells with serum results in an SRE-dependent burst of transcription for a period of 30-45 minutes. However, SRF DNA-binding activity in most cells is constitutive before, during, and after the induction of the gene. Thus, presumably the SRF is either modified itself or interacts

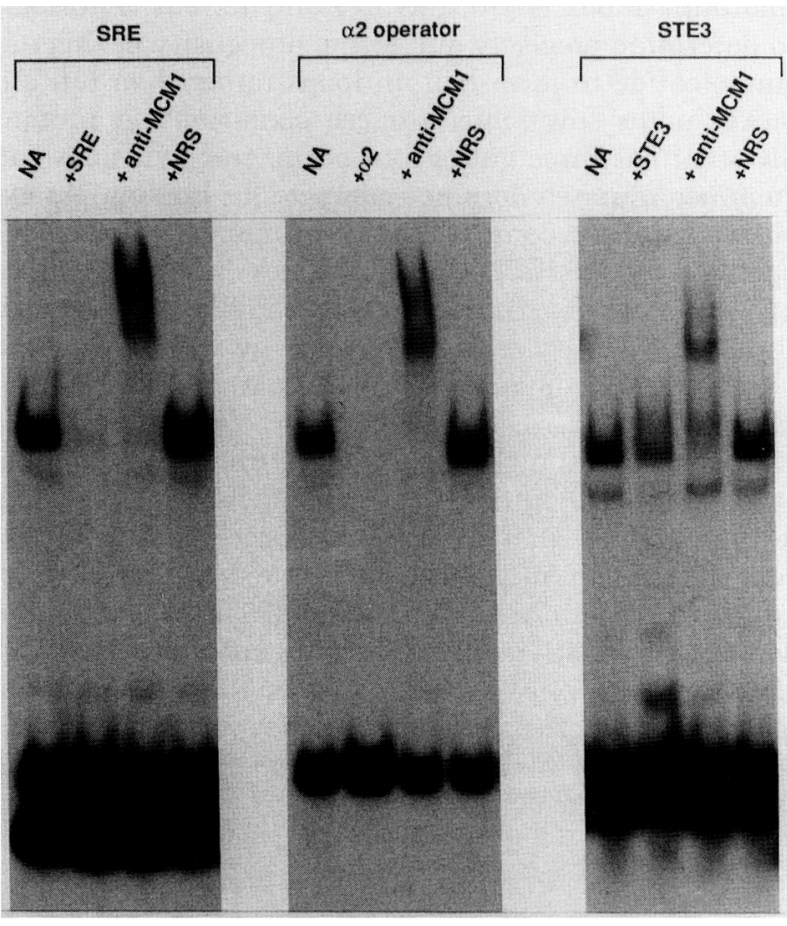

Figure 7. Antisera to $\mathrm{MCM} 1$ reacts with yeast factors that bind to the SRE, the $\alpha 2$ operator, and the UAS of STE3. Doublestranded oligonucleotides to the c-fos SRE, the $\alpha 2$ operator, and the $\alpha$-specific UAS of STE3 were end-labeled and used as probes in band-shift assays with yeast extracts. In the indicated lanes, either unlabeled competitor oligonucleotides ( $\sim 1$ pmole), antisera to MCM1, or normal rabbit serum (NRS) were added to the binding reactions, as described in Materials and methods. (NA) No addition. The yeast extracts used for binding were from a cells for the SRE and $\alpha 2$ probes, and from a/ $\alpha$ diploids for the STE3 probe. 
with another factor whose activity is modulated in response to extracellular stimuli that activate the gene. As yet, no modifications of the SRF or involvement of other proteins with it have been correlated with c-fos transcription (Gilman et al. 1986; Treisman 1986; Hayes et al. 1987b; Sheng et al. 1988).

The human c-fos SRE modulates transcription only very weakly from the yeast $C Y C 1$ promoter. The effects are barely detectable with single copies of the SRE but are amplified when multiple copies of the SRE are positioned at various sites upstream of the promoter. Three copies of the SRE give a weak, but clear, activation of a CYC1 promoter, with no yeast UAS sequences. When copies of the SRE were positioned between the UAS2 and the TATA boxes, up to fivefold reductions in the levels of constitutive transcription were observed. The levels of transcription were still inducible by lactate in these constructs but were overall less than those observed with no SRE (data not shown). This repression was seen in a cells, $\alpha$ cells, and a/ $\alpha$ diploids. Cloning the SRE upstream of the UAS, even in multiple copies, did not lead to repression but, instead, slightly enhanced $\beta$ galactosidase expression. Thus, in yeast, the SRE can modulate CYC1 promoter activity in vivo, but the effects are weak and dependent upon its copy number and relative position.

The operator of the yeast $\alpha 2$ repressor shows similarity to the core sequence of the mammalian SRE. Oligonucleotides made to the sequence of the $\alpha 2$ repressoroperator compete very well for binding of the yeast factor to mammalian SRE. Indeed, they also compete very well for the binding of the mammalian factor to the SRE. However, the yeast complex that was detected in band-shift gels did not appear to be due to the $\alpha 2$ repressor. A similar complex is seen in a cells, which should not be expressing $\alpha 2$, and in extracts of mat ${ }^{-}$ cells, which do not express the mating-type locus gene products. In addition, Sauer et al. (1988) have recently shown that purified $\alpha 2$ repressor binds to the outer portions of the operator sequences that are not homologous to the c-fos SRE sequences (see Fig. 4). Keleher et al. (1988) have shown that another factor, termed GRM, binds to the center region of the $\alpha 2$ operator and is required for repression. It is this molecule and not the $\alpha 2$ repressor that is the likely candidate for the yeast factor that binds to the SRE. Thus, mutations in the center of the $\alpha 2$ operator abolish binding to this factor (Fig. 5). Like the SRE-binding factor, GRM is found in all yeast cell types. In the absence of $\alpha 2$, the $\alpha 2$ operator no longer represses and, instead, becomes a very weak activator (Keleher et al. 1988). This is consistent with the notion that the c-fos SRE in yeast binds GRM, but not $\alpha 2$, and thus does not function as a cell-type-specific repressor, as does the $\alpha 2$ operator.

Bender and Sprague (1987) have reported that UASs in front of $\alpha$-specific genes have a P-box element that is a near-palindromic sequence, with homology to the center of the $\alpha 2$ operator. They have shown that a factor termed PRTF binds to this sequence and cooperates with the $M A T \alpha 1$ gene product to activate $\alpha$-specific gene expres- sion. Like GRM, PRTF is not cell type specific. Because PRTF is a non-cell-type-specific factor and recognizes a sequence with similarities to the core of the $\alpha 2$ operator, it has been suggested that GRM and PRTF are the same protein. Thus, one view of GRM/PRTF is that it functions cooperatively with other cellular proteins either to repress or activate, depending on the cellular and promoter context. This would be consistent with our observations that in yeast, the c-fos SRE, which may be binding only GRM/PRTF, would have only weak activities that are dependent on its location upstream of the CYC1 promoter. This promoter is not regulated in a cell-type-specific manner and thus may not bind factors such as $\alpha 1$ and $\alpha 2$, which normally interact with GRM/ PRTF.

It is also possible that GRM/PRTF and the SREbinding factor are nonidentical proteins with nonidentical functions but with very similar DNA-binding specificities. However, the data presented here with antiMCM1 antibodies, coupled with the known phenotypes of the mcm1-1 mutation, argue that this is unlikely. The c-fos SRE, the $\alpha 2$ repressor-operator, and the UAS of the STE3 gene all give specific bands of similar mobilities on band-shift gels. All three of these regulatory elements cross-compete with each other for formation of the specific complex. All of the specific complexes formed with these three probes shifted in mobility after incubation with anti-MCM1 antisera. Thus, all of these specific complexes must contain MCM1 protein or antigenically related factors.

In addition to these data, the phenotype of the mcm1-1 mutation is consistent with this gene encoding both GRM and PRTF. The mcm1-1 mutation was isolated originally on the basis of its failure to maintain certain minichromosomes, but also has the phenotype of being an $\alpha$-specific sterile. Passmore et al. (1988) have shown that these strains have reduced expression of $\alpha$ specific genes. This phenotype is consistent with the notion of MCM1 encoding PRTF. Although the fact that the null allele of MCM1 is a lethal complicates the biochemistry, Keleher et al. (1988) have reported that the mcm1-1 strain has reduced levels of GRM-binding activity. Thus, the simplest interpretation of all of these observations is that GRM, PRTF, and the yeast SREbinding factor are identical and are encoded by $M C M 1$.

Although the failure of anti-MCM1 antisera to react with the mammalian SRF suggests that the degree of antigenic conservation of the yeast and mammalian factor outside of the DNA-binding domain is not strong, there could still be functional conservation. If so, this would have implications for the biology of each factor. The most obvious implication is that other proteins may interact with SRF to modulate its activity. To date, there is no direct evidence for this, but it would help to explain the paradox that SRF DNA-binding activity does not correlate with c-fos transcription. In this regard, it is interesting to note that the $\alpha 1$ and $\alpha 2$ proteins that interact with GRM/PRTF were first defined genetically and that the biochemical detection of the interaction required overexpression of these proteins (Bender and 
Sprague 1987; Keleher et al. 1988). Thus, analogous factors may be difficult to detect in mammalian cells. However, both GRM- and PRTF-binding sites in yeast are flanked by sequences that appear to be necessary for the cooperative interaction of these factors with $\alpha 1$ and $\alpha 2$. The mammalian SRE appears to be the only sequence necessary for SRF function, although other known protein-binding sites are adjacent to or very near the c-fos SRE (Verma and Sassone-Corsi 1987; SassoneCorsi et al. 1988).

It is obviously an open question whether this type of protein-protein interaction would be conserved through evolution even if the DNA-binding domain were. However, it has been shown recently that subunits of the mammalian CAAT-box-binding factors, which are heteromers, can be individually complemented with their yeast homologs (Chodosh et al. 1988). Thus, there is precedent for such conservation.

A second implication of the discovery of a yeast factor that binds the mammalian SRE is the question of whether this yeast factor, like mammalian SRF, is located in a signal transduction pathway. The yeast mating factors are secreted peptides which, by binding to extracellular receptors, regulate gene expression and cell growth and are thus analogs to mammalian growth factors (Thorner 1981). In fact, many of the cell-type-specific genes of yeast where GRM/PRTF is thought to act are also subject to mating-factor regulation. Jarvis et al. (1988) have shown that a 44-bp oligonucleotide that contains the PRTF-binding site, $\mathrm{P}(S T E 3)$, confers a-factor responsiveness onto a heterologous promoter. However, it must be noted that a yeast consensus element for response to $\alpha$-mating factor, which is distinct from the SRE core sequence, has weak homologies to this a-factor responsive UAS (Kronstad et al. 1987). Nevertheless, it is possible that the yeast SRE-binding factor may play a role in this induction. If so, yeast GRM/PRTF and mammalian SRF could have analogous roles in signal transduction pathways in their respective organisms. Future experiments will address this question directly.

\section{Materials and methods}

Strains and media

a Cells are L3248 (MATa, ura 3-52, trp $\Delta 1$, his 4-34). $\alpha$ Cells are $\mathrm{L} 3256$, and $\mathrm{a} / \alpha$ cells are $\mathrm{L} 3248 \times \mathrm{L} 3256$. These strains are isogenic except at the $M A T$ locus and were obtained from Gerald Fink. The strain used as $M A T^{-}$is L3243 (MAT $\triangle:$ : LEU2 leu 2-3, leu 2-112, ura 3-52, his 4-34). Cells were grown in SD medium (Sherman et al. 1986), supplemented with histidine and tryptophan at $40 \mu \mathrm{g} / \mathrm{ml}$ to maintain selection for the transfected plasmids. Cultures in SD were used to inoculate into SD (lactate) (in which the glucose was replaced with $2 \%$ lactic acid, $\mathrm{pH}$ 6), supplemented with histidine and tryptophan at 40 $\mu \mathrm{g} / \mathrm{ml}$. Hybridoma cells (112-9B10) (Microbiological Associates, Bethesda, Maryland) were grown in DME $/ 5 \%$ fetal calf serum.

\section{Plasmids}

The parent plasmid for all constructs containing the CYC1 UAS2 is $\triangle 265 \mathrm{UP1}$, which was kindly provided by the lab of L.
Guarente and contains the $U R A 3$ gene and the $2 \mu$ origin of replication. It was derived from pLG669Z by deletion of the SmaI fragment, followed by deletion of the CYC1 sequences between the SmaI site $(-314)$ and the HpaII site $(-265)$, regenerating the SmaI site and eliminating UAS1-dependent transcription. The UP1 mutation is a single point mutation in the UAS2 element that results in a 10 -fold increase in the basal activity of the element in vivo. It remains inducible by nonfermentable carbon sources (Guarente et al. 1984). In this plasmid, the CYC1 sequence is fused in frame to the lacZ-coding sequence immediately after the CYC1 ATG. Oligonucleotides were cloned into the unique $X$ hoI site at -177 or the unique SmaI site at -265 ; the UAS2 is at -210 . The parent plasmid for constructs without a UAS was pSX178, also provided by the lab of L. Guarente. It was derived from pLG669Z by deletion of the SmaI fragment and further deletion of the XhoI-SmaI fragment, regenerating the $X h o I$ site. Thus, it is identical to $\triangle 265$ UP1, except for the loss of CYC1 nucleotides -177 to -265 , which include UAS2. Oligonucleotides were cloned into the unique $X h o I$ site at -177 . The SRE oligonucleotides were cloned into this vector by fill in with Klenow fragment and blunt-ended ligation.

Plasmids were transformed into yeast strains, using either the protoplast or $\mathrm{LiCl}$ methods (Sherman et al. 1986).

\section{Oligonucleotides}

Oligonucleotides used in this study have the following sequences:

$$
\begin{aligned}
& \text { SRE 5'-aattCAGGATGTCCATATTAGGACATCTG-3' } \\
& \text { 3'-GTCCTACAGGTATAATCCTGTAGAC c } \mathrm{t} \text { a } \mathrm{g}-5^{\prime} \\
& \text { SRE*(1) 5'-tcgaCAGGATGTGGATATTACCACATCTG-3' } \\
& \text { 3'-GTCCTACACCTATAATGGTGTAGACa } \mathrm{c} \mathrm{t}-5^{\prime} \\
& \mathrm{SRE} \text { *(2) 5'-CAGGATGATCATATTATCACATCTGG } \mathrm{g} \text { a c }-3^{\prime} \\
& 3^{\prime} \text {-catgGTCCTACTAGTATAATAGTGTAGACC-3' } \\
& \alpha 2 \quad 5^{\prime} \text {-tcgaCATGTAATTACCTAATAGGGAAATTTACACGC-3' } \\
& \text { 3'-GTACATTAATGGATTATCCCTTTAAATGTGCGagct-5' } \\
& \alpha 2^{*} \\
& \text { 5'-tcgaCATGTAATTAGGTAATAGCCAAATTTACACGC-3' } \\
& \text { 3'-GTACATTAATCCATTATCGGTTTAAATGTGCGagct-5' } \\
& \text { P(STE }) \quad 5^{\prime} \text {-tcgaCACACTAATTAGGAAGC-3' } \\
& \text { 3'-GTGTGATTAATCCTTCG a g c t -5' } \\
& \text { STE3 5'-tcgaCTGTCATTGTGACACTAATTAGGAAA-3' } \\
& 3^{\prime} \text {-GACAGTAACACTGTGATTAATCCTTT a } \mathrm{g} \mathrm{t}-5^{\prime}
\end{aligned}
$$

SRE is from the human c-fos gene (Treisman 1986). SRE* $(1)$ and $S^{*}{ }^{*}(2)$ are quadruple point mutations of the SRE that do not bind SRF. SRE*(2) was used in Figure 5; $\operatorname{SRE}^{\star}(1)$ was used in Figures 1 and $6 . \alpha 2$ is the operator of the STE6 gene of $S$. cerevisiae (Johnson and Herskowitz 1985). $\alpha 2^{*}$ is a quadruple point mutant of the $\alpha 2$ operator. $\mathrm{P}(S T E)$ is the P box of the $\alpha$-specific STE3 gene (Bender and Sprague 1987). STE3 is the $\alpha$-specific UAS of the STE3 gene; it contains both the $\mathrm{P}$ and $\mathrm{Q}$ boxes (Jarvis et al. 1988). Nucleotides indicated in lowercase letters are not sequences from the above genes but are the termini of convenient restriction sites appended to each oligonucleotide.

\section{Extracts and DNA-binding assays}

Nuclear extracts of 112-9B10 hybridoma cells were prepared according to Dignam et al. (1983). Yeast whole-cell extracts were prepared by disruption of the cells with glass beads. Cultures 
were grown in YEPD to $\mathrm{OD}_{600} \sim 1.0$. Cells were pelleted by centrifugation, washed in cold extraction buffer $[200 \mathrm{mM}$ Tris $(\mathrm{pH}$ 8), $400 \mathrm{mM}\left(\mathrm{NH}_{4}\right)_{2} \mathrm{SO}_{4}, 10 \mathrm{~mm} \mathrm{MgCl} 2,1 \mathrm{~mm}$ EDTA, $10 \%$ glycerol, $1 \mathrm{mM}$ dithiothreitol (DTT), supplemented with $0.5 \mathrm{~mm}$ phenylmethylsulfonyl fluoride (PMSF) and $2 \mu \mathrm{g} / \mathrm{ml}$ each of leupeptin, pepstatin A, chymostatin, and antipain] and resuspended in one volume of cold extraction buffer. Packed cell volumes $(1.5 \times)$ of $0.4-\mathrm{mm}$ glass beads were added, and the mixture vortexed for $1 \mathrm{~min}$ and placed on ice for $1 \mathrm{~min}$. This step was repeated 10 times. Two volumes of extraction buffer were added, and the mixture was incubated for $30 \mathrm{~min}$ on ice and centrifuged for $10 \mathrm{~min}$ at $10,000 \mathrm{rpm}$ in a Sorvall SS-34 rotor at $4^{\circ} \mathrm{C}$. Saturated $\left(\mathrm{NH}_{4}\right)_{2} \mathrm{SO}_{4}$ was added to the supernatant to a final concentration of $40 \%$ saturation, and the mixture was stirred for $30 \mathrm{~min}$ at $4^{\circ} \mathrm{C}$ and centrifuged $20 \mathrm{~min}$ at $10,000 \mathrm{rpm}$ in a Sorvall SS-34 rotor at $4^{\circ} \mathrm{C}$. The pellet was resuspended in one-eighth volume of dialysis buffer [ $20 \mathrm{mM}$ HEPES (pH 8), 5 mM EDTA, 20\% glycerol, $1 \mathrm{mM} \mathrm{DTT}$, supplemented with 0.5 $\mathrm{mM}$ PMSF and $0.2 \mu \mathrm{g} / \mathrm{ml}$ each of leupeptin, pepstatin A, chymostatin, and antipain, and dialyzed against 500 volumes of dialysis buffer for $4 \mathrm{hr}$ at $4^{\circ} \mathrm{C}$. Extracts were aliquoted and stored at $-80^{\circ} \mathrm{C}$. Protein concentrations were determined using the Bio-Rad protein assay kit.

DNA-binding assays were performed by mixing nuclear or whole-cell extracts, end-labeled probe $(8000 \mathrm{cpm}, \sim 0.1-0.5 \mathrm{ng})$, carrier DNA [ $1 \mu \mathrm{g}$ of poly $(\mathrm{dI}-\mathrm{dC}) \cdot$ poly $(\mathrm{dI}-\mathrm{dC})$ for hybridoma extracts or $0.5 \mu \mathrm{g}$ of sheared salmon sperm DNA for yeast extracts] and competitor DNA and incubating for $30 \mathrm{~min}$ at $30^{\circ} \mathrm{C}$ in a final volume of $15-20 \mu \mathrm{l}$ of $10 \mathrm{~mm}$ HEPES $\langle\mathrm{pH} 7.9$ ), $50 \mathrm{~mm}$ $\mathrm{NaCl}, 1 \mathrm{~mm}$ DTT, $1 \mathrm{~mm}$ EDTA, and $10 \%$ (vol/vol) glycerol. Extract was added to the mixture last. Samples were layered onto $4 \%$ acrylamide gels (acrylamide/bis at $80: 1$ ) and electrophoresed at $10 \mathrm{~V} / \mathrm{cm}$ in $6.7 \mathrm{~mm}$ Tris $(\mathrm{pH} 7.9), 3.3 \mathrm{~mm}$ sodium acetate, and $1 \mathrm{mM}$ EDTA, with buffer recirculation between the electrode chambers at $50 \mathrm{ml} / \mathrm{min}$. Gels were fixed in $10 \%$ acetic acid $/ 10 \%$ methanol, dried, and exposed to X-ray film.

For band shifts with antisera added, binding reactions were performed as described above, and the antisera were added to a final dilution of $1: 100(\sim 0.2 \mathrm{mg} / \mathrm{ml}$ protein). The reaction was then incubated for an additional $20 \mathrm{~min}$ prior to electrophoresis. Polyclonal rabbit antisera to MCMl was a gift of Steven Passmore and Bik-Kwoon Tye (Cornell University) and was made to an Escherichia coli-produced MCM1- $\beta$-galactosidase fusion protein.

\section{Methylation interference}

Methylation interference at $G$ residues was performed as in Hayes et al. (1987a). Briefly, an SRE oligonucleotide inserted into the SmaI site of pUC18 was digested with either PstIEcoRI or SacI-HindIII and end-labeled. The resulting probe was methylated by treatment with dimethylsulfate and incubated with extracts as above. Bound and free probe were resolved by electrophoresis, as described above, and labeled probe recovered from each band. Recovered, methylated DNA was cleaved with piperidine and analyzed on a DNA sequencing gel.

\section{$\beta$-Galactosidase assays}

Yeast cultures in SD or SD (lactate) were centrifuged, resuspended in buffer $Z$, and stored at $-20^{\circ} \mathrm{C}$. Assays were performed as described by Miller (1972), except that cells were permeabilized by vortexing with $20 \mu \mathrm{CHCl}_{3}$ and $20 \mu \mathrm{l} 0.1 \%$ SDS per $800 \mu \mathrm{l}$. Activity is calculated as $\left(\mathrm{OD}_{420} \times 1000\right) /$ $\left[\mathrm{OD}_{600} \times\right.$ time $\left.(\mathrm{min}) \times \mathrm{V}(\mathrm{ml})\right]$, where $\mathrm{V}(\mathrm{ml})$ is the volume of culture used in the assay.

\section{Acknowledgments}

We thank Gerald Fink and Leonard Guarante and members of their laboratories, especially Fred Dietrich and Jim Olesen, for provisions of plasmids, strains, and invaluable advice. We would also like to thank Steven Passmore and Bik-Kwoon Tye for communication of unpublished results and donation of anti-MCM1 antisera. We are grateful to Phillip Sharp and Earl Ruley for critical reading of the manuscript and to Karen Traite for preparing it. T.E.H. is a fellow of the American Cancer Society. B.H.C. is a Searle Scholar and a Rita Allen Scholar. This work was supported, in addition, by grants to B.H.C. from the National Institutes of Health.

\section{References}

Bender, A. and G.F. Sprague. 1987. Mat $\alpha 1$ protein, a yeast transcription activator, binds synergistically with a second protein to a set of cell-type-specific genes. Cell 50: 681-691.

Brent, R. 1985. Repression of transcription in yeast. Cell 42: $3-4$.

Buratowski, S., S. Hahn, P.A. Sharp, and L. Guarente. 1988. Function of a yeast TATA element-binding protein in a mammalian transcription system. Nature 334: 37-42.

Cavallini, B., J. Huet, J.-L. Plassat, A. Sentenac, J.-M. Egly, and P. Chambon. 1988. A yeast activity can substitute for the HeLa cell TATA box factor. Nature 334: 77-80.

Chodosh, L.A., J. Olesen, S. Hahn, A.S. Baldwin, L. Guarente, and P.A. Sharp. 1988. A yeast and a human CCAAT-binding protein have heterologous subunits that are functionally interchangeable. Cell 53: 25-35.

Cochran, B.H. 1985. The molecular action of platelet-derived growth factor. Adv. Cancer Res. 45: 183-216.

Cochran, B.H., J. Zullo, I.M. Verma, and C.D. Stiles. 1984. Expression of the c-fos gene and of a fos-related gene is stimulated by platelet-derived growth factor. Science 226: 10801082.

Dignam, J.D., R.M. Lebovitz, and R.G. Roeder. 1983. Accurate transcription initiation by RNA polymerase II in a soluble extract from isolated mammalian nuclei. Nucleic Acid. Res. 11: $1475-1489$.

Dubois, E., J. Bercy, F. Descamps, and F. Messenguy. 1987. Characterization of two genes essential for vegetative growth in Saccharomyces cerevisiae: Nucleotide sequence determination and chromosome mapping. Gene 55: 265275.

Fisch, T.M., R. Prywes, and R.G. Roeder. 1987. c-fos sequences necessary for basal expression and induction by epidermal growth factor, TPA, and calcium ionophore. Mol. Cell. Biol. 7: 3490-3502.

Garner, M.M. and A. Revzin. 1981. A gel electrophoresis method for quantifying the binding of proteins to specific DNA regions: Application to components of the Escherichia coli lactose operon regulatory system. Nucleic Acid. Res. 9: 3047-3060.

Gilman, M.Z. 1988. The c-fos serum response element responds to protein kinase c-dependent and -independent signals, but not to cyclic AMP. Genes Dev. 2: 394-402.

Gilman, M.Z., R.N. Wilson, and R.A. Weinberg 1986. Multiple protein binding sites in the 5 '-flanking region regulate c-fos expression. Mol. Cell. Biol. 6: 4305-4316.

Greenberg, M.E. and E.B. Ziff. 1984. Stimulation of 3T3 cells induces transcription of the c-fos proto-oncogene. Nature 311: 433-442.

Greenberg, M.E., Z. Siegfried, and E.B. Ziff. 1987. Mutation of the c-fos gene dyad symmetry element inhibits serum indu- 
cibility of transcription in vivo and the nuclear regulatory factor binding in vitro. Mol. Cell. Biol. 7: 1217-1225.

Guarente, L. and T. Mason. 1983. Heme regulates transcription of the CYC1 gene of Saccharomyces cerevisiae via an upstream activation site. Cell 32: 1279-1286.

Guarente, L., B. Lalonde, P. Gifford, and E. Alani. 1984. Distinctly regulated tandem upstream activation sites mediate catabolite repression of the CYC1 gene of Saccharomyces cerevisiae. Cell 36: 503-511.

Harshman, K.D., W.S. Moye-Rowley, and C.S. Parker. 1988. Transcriptional activation by the SV40 AP-1 recognition element in yeast is mediated by a factor similar to AP- 1 that is distinct from GCN4. Cell 53: 321-330.

Hayes, T.E., A.M. Kitchen, and B.H. Cochran. 1987a. Inducible binding of a factor of the c-fos regulatory region. Proc. Natl. Acad. Sci. 84: 1272-1276.

- $1987 \mathrm{~b}$. A rapidly inducible DNA-binding activity which binds upstream of the c-fos proto-oncogene. I. Cell. Physiol. (Suppl.) 5: 63-68.

Jarvis, E.E., D.C. Hagen, and G.F. Sprague. 1988. Identification of a DNA segment that is necessary and sufficient for $\alpha$-specific gene control in Saccharomyces cerevisiae: Implications for regulation of $\alpha$-specific and $\alpha$-specific genes. Mol. Cell. Biol. 8: 309-320.

Johnson, A.D. and I. Herskowitz. 1985. A repressor (MAT $\alpha 2$ product) and its operator control expression of a set of cell type specific genes in yeast. Cell 42: 237-247.

Jones, R.H., S. Moreno, P. Nurse, and N.C. Jones. 1988. Expression of the SV40 promoter in fission yeast: Identification and characterization of an AP-1-like factor. Cell 53: 659667.

Kakidani, H. and M. Ptashne. 1988. GAL4 activates gene expression in mammalian cells. Cell 52: 161-167.

Keleher, C.A., C. Goutte, and A.D. Johnson. 1988. The yeast cell-type-specific repressor $\alpha 2$ acts cooperatively with a non-cell-type-specific protein. Cell 53: 927-936.

Kronstad, J.W., J.A. Holly, and V.L. MacKay. 1987. A yeast operator overlaps an upstream activation site. Cell 50: 369-377.

Maine, G.T., P. Sinha, and B.-K. Tye. 1984. Mutants of S. cerevisiae defective in the maintenance of minichromosomes. Genetics 106: 365-385.

Miller, J. 1972. Experiments in molecular genetics Cold Spring Harbor Laboratory, Cold Spring Harbor, New York.

Mohun, T., N. Garrett, and R. Treisman. 1987. Xenopus cytoskeletal actin and human c-fos gene promoters share a conserved protein-binding site. EMBO I. 6: 667-673.

Muller, R., R. Bravo, J. Burckhardt, and T. Curran. 1984. Induction of $\mathrm{c}-f \circ$ gene and protein by growth factors precedes activation of c-myc. Nature 312: 716-720.

Passmore, S., G.T. Maine, R. Elble, C. Christ, and B.-K. Tye. 1988. A Saccharomyces cerevisiae protein involved in plasmid maintenance is necessary for mating of MAT $\alpha$ cells. J. Mol. Biol. (in press).

Prywes, R. and R.G. Roeder. 1986. Inducible binding of a factor to the c-fos enhancer. Cell 47: 777-784.

- 1987. Purification of the c-fos enhancer binding protein. Mol. Cell. Biol. 7: 3482-2489.

Sassone-Corsi, P., J.C. Sisson, and I.M. Verma. 1988. Transcriptional autoregulation of the proto-oncogene fos. Nature 334: 314-319.

Sauer, R.T., D.L. Smith, and A.D. Johnson. 1988. Flexibility of the yeast $\alpha 2$ repressor enables it to occupy the ends of its operator leaving the center free. Genes Dev. 2: 807-816.

Sheng, M., S.T. Dougan, G. McFadden, and M.E. Greenberg. 1988. Calcium and growth factor pathways of c-fos transcriptional activation require distinct upstream regulatory sequences. Mol. Cell. Biol. 8: 2787-2796.

Sherman, F., G.F. Fink, and J.B. Hicks. 1986. Methods in yeast genetics. Cold Spring Harbor Laboratory, Cold Spring Harbor, New York.

Singh, H., R. Sen, D. Baltimore, and P.A. Sharp. 1986. A nuclear factor that binds to a conserved sequence motif in transcriptional control elements of immunoglobulin genes. Nature 319: 154-158.

Struhl, K. 1987. The DNA-binding domains of the jun oncoprotein and the yeast GCN4 transcriptional activator protein are functionally homologous. Cell 50: 841-846.

Thorner, J. 1981. Pheromonal regulation of development in Saccharomyces cerevisiae. In Molecular biology of the yeast Saccharomyces. Life cycle and inheritance led. J.N. Strathern, E.W. Jones, and J.R. Broach), pp. 143-180. Cold Spring Harbor Laboratory, Cold Spring Harbor, New York.

Treisman, R. 1985. Transient accumulation of c-fos RNA following serum stimulation requires a conserved 5 ' element and c-fos 3'sequences. Cell 42: 889-902.

- 1986. Identification of a protein-binding site that mediates transcriptional response of the c-fos gene to serum factors. Cell 46: 567-574.

1987. Identification and purification of a polypeptide that binds to the c-fos serum response element. $E M B O J$. 6: $2711-2717$.

Verma, I.M. and P. Sassone-Corsi. 1987. Proto-oncogene fos: Complex but versatile regulation. Cell 51: $513-514$.

Webster, N., J.R. Jin, S. Green, M. Hollis, and P. Chambon. 1988. The yeast $\mathrm{UAS}_{\mathrm{G}}$ is a transcriptional enhancer in human HeLa cells in the presence of the GAL4 trans-activator. Cell 52: 169-178.

Wiederrecht, G., D.J. Shuey, W.A. Kibbe, and C.S. Parker. 1987. The Saccharomyces and Drosophila heat shock transcription factors are identical in size and DNA binding properties. Cell 48: 507-515. 


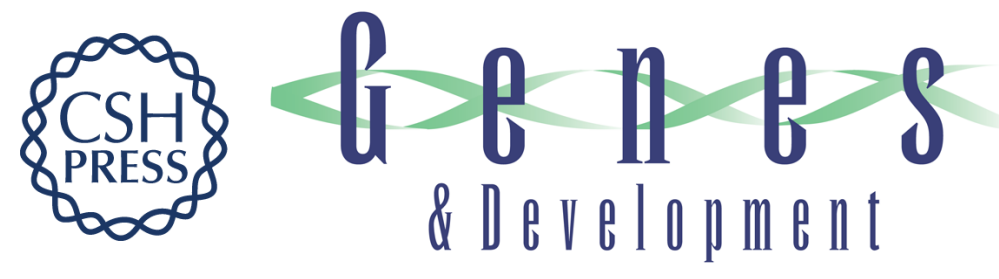

\section{The human c-fos serum response factor and the yeast factors GRM/PRTF have related DNA-binding specificities.}

T E Hayes, P Sengupta and B H Cochran

Genes Dev. 1988, 2:

Access the most recent version at doi:10.1101/gad.2.12b.1713

References This article cites 41 articles, 10 of which can be accessed free at:

http://genesdev.cshlp.org/content/2/12b/1713.full.html\#ref-list-1

License

Email Alerting

Service right corner of the article or click here.

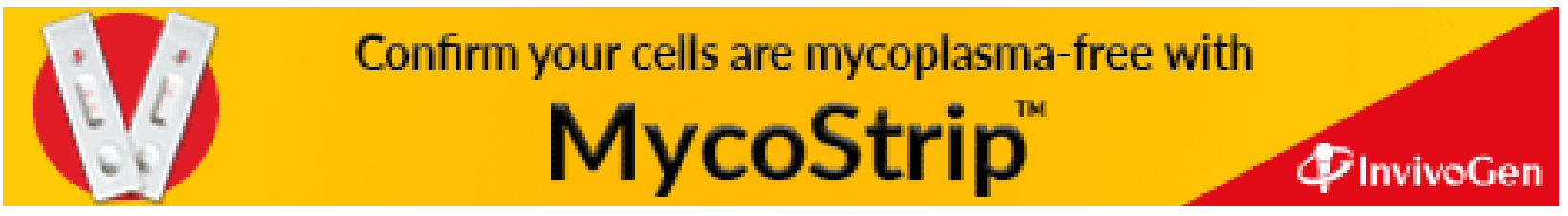

